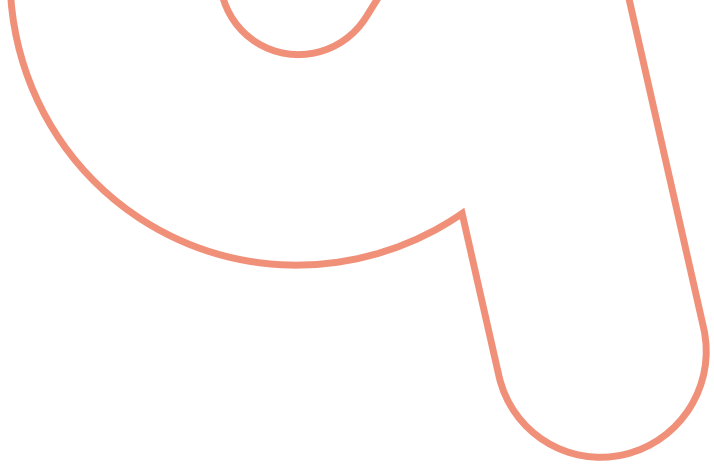

\title{
Emotional design model as alternative for access of products from Huila to Colombian coffee market
}

\author{
Johans Sánchez Murillas \\ Universidad Nacional de Colombia \\ josanchezmu@unal.edu.co \\ X \\ Joan Sebastián Martinez Barco \\ Colegio Colombo Británico \\ jsmartinezb@unal.edu.com $\mathbf{x}$ \\ Lina Marcela Pinchao Díaz \\ Universidad Nacional de Colombia \\ lina.pinchao@ccbcali.edu.co $\mathbf{x}$
}

PROJËTICA

\section{COMO CITAR ESTE ARTIGO:}

MURILLAS, Johans Sánchez; BARCO, Joan Sebastián Martinez; DÍAZ, Lina Marcela Pinchao. Emotional design model as alternative for access of products from Huila to Colombian coffee market. Projética, Londrina, v. 11, n. 3, p. 225-245, Nov. 2020. Edição especial FDaP. DOI: 10.5433/2236-2207.2020v11n3esp.p225. ISSN: 2236-2207.

DOI: 10.5433/2236-2207.2020v11n3esp.p225 
ABSTRACT: The cluster of coffee in Colombia is distinguished by two sub - nucleus that constitutes character of consolidated product in two ways: those coffee nucleuses which line reaches the marketable product with accepted national reference level identity and ruled by "coffee culture", and those producers who are primarily suppliers of the previous ones since its strength is not in intervention strategies development from design. The present investigation exposes the application of design methodology by Kansei engineering (KE) focused on aestheticformal development of products that connect emotionally with consumers inside the coffee cluster of Huila, Colombia. Methodology follows the Design for Aesthetics technique, the result is a set of statistics relations between emotional impressions of the potential consumers over a product and its aesthetic-formal properties. This methodology looks to build a model of briefing that allows develop products that connect with the user in an aesthetic-emotional way, by pretending to obtain a requirements and design parameters identification and definition, and to build a relation more accurate between products and consumers, as well. Methodology indicated is specified applying it to a coffee packaging design, developed for a new indigenous coffee brand, with the propose to create a high competitive product, with the advantage that is based on emotional linkage with potential customers.

Keywords: Emotional design. Coffee culture. Kansei engineering. Properties space. semantic differential.

\section{INTRODUCTION}

Colombian coffee industry is one of the most recognized machineries of the country (BURITICA, 2010). Inside the Colombian coffee cluster, there exist different productive sub-nucleus disseminated by all the territory, placed in departments regions of Antioquia, Boyacá, Caldas, Cauca, Cesar, Caquetá, Casanare, Cundinamarca, 
Guajira, Huila, Magdalena, Meta, Nariño, Northern Santander, Quindío, Risaralda, Santander, Tolima and northeast of the Valle del Cauca; each with its geographical, botanic and demographic singularities (FEDERACIÓN NACIONAL DE CAFETEROS DE COLOMBIA, 2010), that constitutes the consolidated product character in two ways: those coffee nucleuses which line reaches the marketable product with accepted national reference level identity and other producers who are primarily suppliers of the previous ones, since its strength is not in value strategies development, as brand identity and consumer experience, but these reside in process and product quality (TRUEMAN; JOBBER, 1998).

Has been usual to attribute the denomination "coffee culture" (PAISAJE NATURAL CAFETERO, 2017) to coffee region zones (Caldas, Risaralda, Quindío) and Antioquia, been considered top coffee grower marketers and producers in Colombia. The previous distribution represents a slant for the broad coffee market placed in different country zones. In consequence, the market of zones placed in departments as Cauca, Caquetá, Huila and Nariño; whose product has characteristics of quality excellence, because its flavor and aroma, overcoming even previous mentioned segment, are underestimated and recognized as lower or nonexistent in the so called "coffee culture" (SEMANATE, 2014).

The present study proposes that inside the productive and commercial process of this last brands, are adapted methodologies that points to different consumption experience levels, as used in emotional design that can provide differential value and attributes to product formal configuration. The use of this methodologies pretends a higher market participation, as advantage over a series of products that exists in a marketing place (HUANG et al., 2014). With this intention, this investigation is supported on application of Kansei Engineering (KE), a product emotional design philosophy proposed by Nagamachi $(1995,1999,2002,2008)$ considered as most useful methodology in manage of emotional requirements of 
consumer (HUANG et al., 2014), this methodology proposes the semiotic studies for formal interpretation of consumption products.

The ways to project the design differs on methodological processes that designer uses (CROSS, 2005), because from the decade of 2000 the role of design is focused in ensure leadership of a new product in the market. (PERKS; COOPER; JONES, 2005). This, as well, implies that communicative design processes are important to satisfy the needs exposed in markets. Briede Westermeyer, Cabello Moro and Hernandis Ortuño (2014) defines design as "an activity that not only has to consider the exercise projection that pretends landing and specify ideas, but consideration and integration of multiple factors of diverse orders and contexts from a multiple dimension perspective oriented to manufacturing and production".

For developing of this study, was selected the coffee producer case, Alicafeh (Huila coffee growers' alliance in Spanish), placed in Huila, department located at $377 \mathrm{Km}$ to the south of Bogotá; in rural zones of this department, little local coffee marketers and producers, perform their work keeping up a narrow market by a low demand and a high competence that threats their livelihood (SEMANATE, 2017). For 2018, department of Huila is recognized as the higher coffee producer, with a representation of $18 \%$ over total produced by the country, likewise, Huila is recognized with the "Cup of excellence" award, by its quality and sustainability productive considerations (LA REPÚBLICA, 2019).

\section{METHODOLOGY}

For purposes of the study, methodology consisted on application of 5 stages: first stage corresponded to an application domain election of Kansei methodology where field of study of packing design were selected. Second stage for semantic space selection that conducted to emotional design nature under the study of 8 
portfolios of products present in Huila's coffee market. In the third stage, properties space of 5 samples of coffee packing was identified that defines composite morphological qualities of design. Fourth stage corresponded to synthesis under the QT1 technique that stablishes relations among formal and emotional qualities present in the packing; and ultimately, fifth stage analyzes results of the synthesis for the construction of a briefing model that will play as a guide for future prototyped design of packing.

\subsection{Selection of Kansei Domain for Application}

According with product release requirements commercialized by Alicafeh known as Yanakuna Coffee, an indigenous coffee that, among its principles, saves the natural coffee product. This principle is taken as reference to make up the Kansei Domain (KD) for building a briefing model. $K D$ can be described as the idea and action field more accurate for the abstract structure design process of a product (Fig. 1.), evidenced in products tangible representations (AVENDAÑO PRIETO; ÁLVAREZ, 2013).

Fig. 1 - General Kansei methodology in relation to design process.

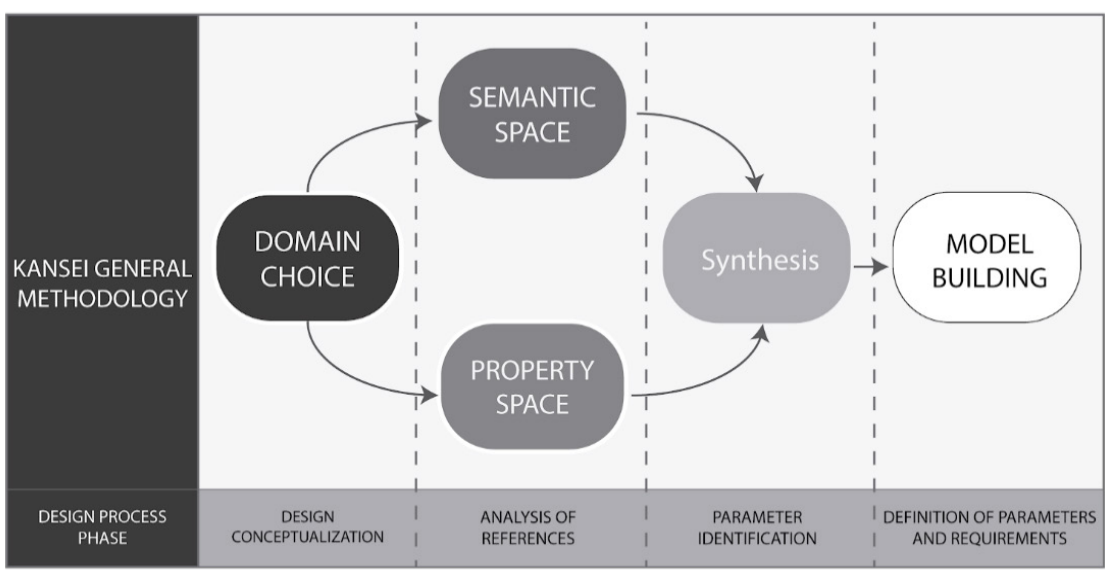

Fonte: Own elaboration. 


\subsection{Data Capture for Emotions Design from Formal Configuration: Semantic Space}

6 product portfolios of enterprises at national level were analyzed, that commercialize its coffee under the "natural and sustainable" denomination, with the aim to identify most recurrent words in textual descriptions of different coffee products inside the market, a 48 words sample was taken recognized in this study as Kansei Terms (KTe) later grouped for an affinity analysis according it conceptual definition, obtaining a reduction of 7 Kansei Tags (KT) (Fig. 2.), used for Semantic Differential (SD) analysis in 5 reference samples of Huila's coffee packing. SD seeks to compare between products of same category, literal definitions of viewers to objects, achieving defining adjectives and or opposite concepts in a product with the aim to evaluate which one fulfill in most conditions the definition of an adjective (HUANG; CHEN; KHOO, 2012a, 2012b). Results of application of SD will be the base to establish in Semantic Space (SS).

The instrument was submitted to a 121 people sample and this information was used as supporting material for making surveys composed by demographic questions. Inside its structure, the instrument had a dedicated section to application of SD (KHEAN CHUAN et al., 2013), whose propose was to compare all of 5 products, (Fig. 3.), to evaluate formal configuration options and different variants in corresponding with the $K T$.

This instrument was developed using the Design for Aesthetics technique (CÓRDOBA-ROLDÁN; AGUAYO-GONZÁLEZ; LAMA-RUIZ, 2010), that seeks to capture relationship metrics between adjectives and or concepts expressed by consumers from generated impression by the 7 KT (NAGAMACHI, 1995, 1999, 2002, 2008). (Fig. 4.). 
Fig. 2 - Affinity analysis of Kansei Terms for selection of Kansei Tags.

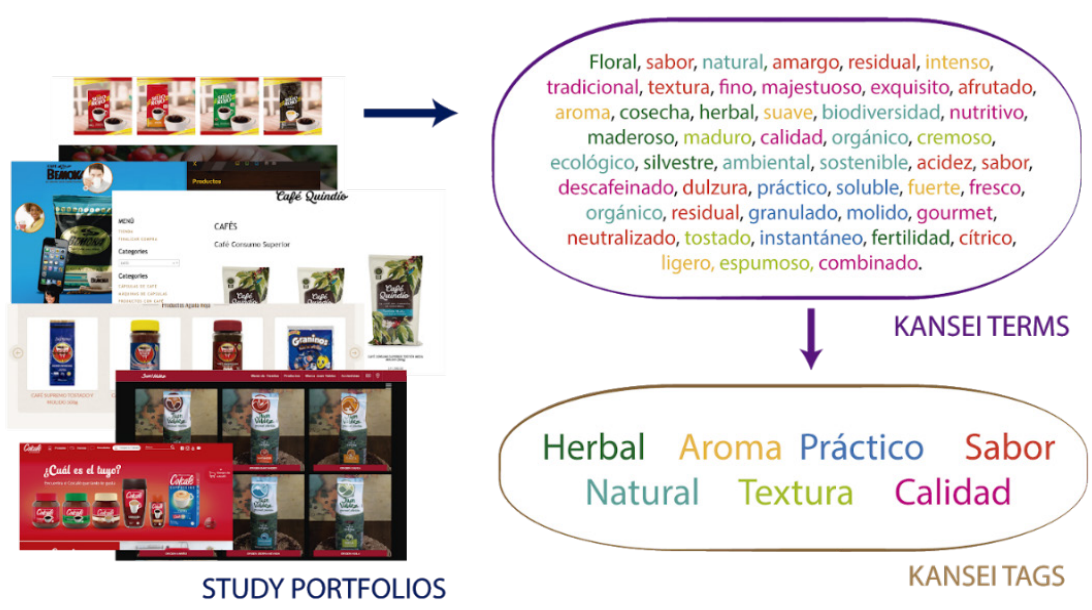

Font: Own elaboration.

Fig. 3 - Coffee packing used as formal reference samples.

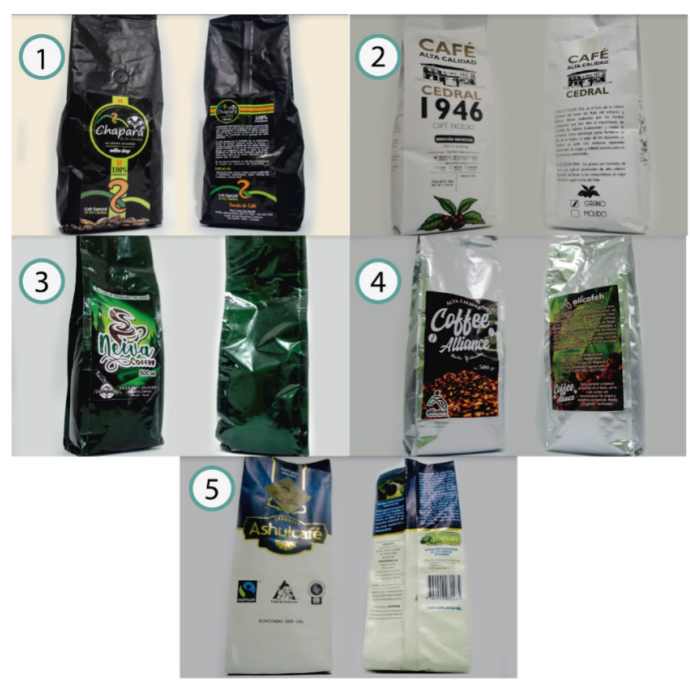

Font: Own elaboration. 
Fig. 4 - Example of semantic differential.

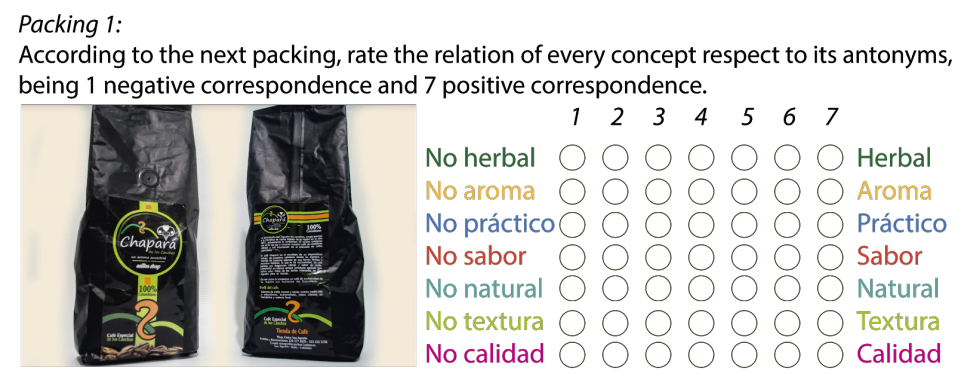

Font: Own elaboration.

\subsubsection{Properties Space}

The Properties Space (PS) identifies all the product morphological properties with which it's intended to infer determined emotions. In this study, selected properties were directly related with the 5 packing samples, used to identify characteristic formal patterns of local region factor, by formal comparatives that contained attributes as silhouettes, colors, textures, graphic languages, distribution and visual elements concentration. (Fig. 5.).

Fig. 5 - Example of formal analysis of one sample packing.

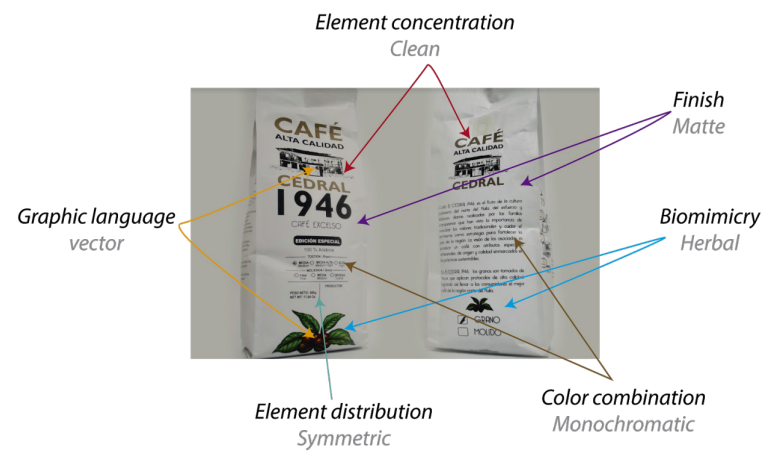

Font: Own elaboration. 
Table 1 - Properties and sub-properties that conforms the properties space.

\begin{tabular}{|c|c|c|c|}
\hline PROPERTY SPACE & & & \\
\hline PROPERTY & SUB - PROPERTY & & \\
\hline $\mathrm{P}_{1}$ :Graphic language & $\mathrm{P}_{1.1}:$ Photography & $\mathrm{P}_{1.2}:$ Vector & \\
\hline $\mathrm{P}_{2}:$ Biomimicry & $\mathrm{P}_{2.1}:$ Zoomorphic & $\mathrm{P}_{2.2}:$ Herbal & \\
\hline $\mathrm{P}_{3}$ :Finish & $\mathrm{P}_{3.1}:$ Glossy & $\mathrm{P}_{3.2}:$ Matte & \\
\hline $\mathrm{P}_{4}:$ Element Distribution & $\mathrm{P}_{4.1}:$ Symmetry & $\mathrm{P}_{4.2}:$ Asymmetry & \\
\hline $\mathrm{P}_{5}$ :Element Concentration & $\mathrm{P}_{5.1}:$ Saturated & $\mathrm{P}_{5.2}:$ Clean & \\
\hline $\mathrm{P}_{6}:$ Color combination & $\mathrm{P}_{6.1}:$ Monochromatic & $\mathrm{P}_{6.2}$ :Complementary & $\mathrm{P}_{6.3}:$ Analogous \\
\hline
\end{tabular}

Font: Own elaboration.

\subsubsection{Synthesis: Relationship Between Semantic Space and Properties Space}

Once identified and evaluated the values of SS and PS, the synthesis phase was proceeded. Synthesis seeks to establish direct relationships between Kansei values and recognized formal qualities, using QT1 model technique. The QT1 quantitation technique was developed by Chikio Hayashi, where using statistics it can be predicted relationships between a quantitative value and categorical variables using the multiple regression method (CÓRDOBA-ROLDÁN; AGUAYO-GONZÁLEZ; LAMA-RUIZ, 2010).

\subsection{Model Construction: Briefing Quantitative Model}

Results obtained by QT1 synthesis were taken as a requirements series that enable the construction of formal models according to emotional qualities of $K T$, this was interpreted as the briefing model to establish parameters and guidelines of compositional order inside the design prototyped proposes. 


\section{RESULTS: STUDY CASE COFFEE PACKAGING DESIGN BY KI FOR AESTHETICS}

First result expressed by the instrument, it's composed from qualifications expressed by sample consumers respect to tags correspondence of semantic space in the 5 Huila's market products samples. The evaluation used in this result is taken according to the sample of most representative mode by consumers in each $K T$ and in each packing tested. The representation evidenced connections between design elements and KT (CÓRDOBA-ROLDÁN; AGUAYO-GONZÁLEZ; LAMA-RUIZ, 2010), sorting relationships in the most appropriate way expressed by the sample. (Fig. 4.).

Table 2 - Correspondence between market reference products and semantic space tags.

\begin{tabular}{|c|c|c|c|c|c|c|c|}
\hline $\begin{array}{l}\boldsymbol{K} \boldsymbol{T} \\
P a c\end{array}$ & $\begin{array}{l}K T_{i}: \\
\text { HERBAL }\end{array}$ & $\begin{array}{l}K T_{2}: \\
\text { SMELLS }\end{array}$ & $\begin{array}{l}K T_{3}: \\
\text { PRACTICAL }\end{array}$ & $\begin{array}{l}K T_{4}: \\
\text { TASTE }\end{array}$ & $\begin{array}{l}K T_{5}: \\
\text { NATURAL }\end{array}$ & $\begin{array}{l}K T_{6}: \\
\text { TEXTURE }\end{array}$ & $\begin{array}{l}K T_{7}: \\
\text { QUALITY }\end{array}$ \\
\hline E1 & 1 & 5 & 3 & 6 & 3 & 6 & 6 \\
\hline E2 & 7 & 5 & 5 & 6 & 6 & 6 & 7 \\
\hline E3 & 3 & 5 & 3 & 3 & 3 & 3 & 3 \\
\hline E4 & 3 & 5 & 5 & 3 & 6 & 5 & 6 \\
\hline E5 & 3 & 5 & 6 & 6 & 4 & 6 & 6 \\
\hline
\end{tabular}

Font: Own elaboration.

The second result corresponds to identification of variables owned by $P S$ that belong to morphological construction of packing samples analyzed. For making properties evaluation and correlations in sub-properties, dummy variables technique was used (ALONZO; MUÑOZ, 2014), which are dichotomous qualitative variables that assumes values $(0 ; 1)$, indicating exclusive belonging to one and only category of the property. 
Table 3 - Correspondence between market referent products and formal properties and sub-properties present in its formal configuration.

\begin{tabular}{lllllllllllllll}
\hline PROPERTY & \multicolumn{2}{c}{$\boldsymbol{P}_{1}$} & \multicolumn{2}{c}{$\boldsymbol{P}_{2}$} & \multicolumn{2}{c}{$\boldsymbol{P}_{3}$} & \multicolumn{2}{c}{$\boldsymbol{P}_{4}$} & \multicolumn{2}{c}{$\boldsymbol{P}_{5}$} & & $\boldsymbol{P}_{6}$ \\
& & & & & & & & \\
SUB-PROPERTY & $\boldsymbol{P}_{1.1}$ & $\boldsymbol{P}_{1.2}$ & $\boldsymbol{P}_{2.1}$ & $\boldsymbol{P}_{2.2}$ & $\boldsymbol{P}_{3.1}$ & $\boldsymbol{P}_{3.2}$ & $\boldsymbol{P}_{4.1}$ & $\boldsymbol{P}_{4.2}$ & $\boldsymbol{P}_{5.1}$ & $\boldsymbol{P}_{5.2}$ & $\boldsymbol{P}_{6.1}$ & $\boldsymbol{P}_{6.2}$ & $\boldsymbol{P}_{6.1 .3}$ \\
\hline PACKING & & & & & & & & & & & & \\
\hline E1 & 0 & 1 & 1 & 0 & 1 & 0 & 0 & 1 & 1 & 0 & 0 & 1 & 0 \\
\hline E2 & 0 & 1 & 0 & 1 & 1 & 0 & 1 & 0 & 0 & 1 & 1 & 0 & 0 \\
\hline E3 & 0 & 1 & 1 & 0 & 0 & 1 & 0 & 1 & 1 & 0 & 0 & 1 & 0 \\
\hline E4 & 1 & 0 & 0 & 1 & 0 & 1 & 0 & 1 & 1 & 0 & 0 & 1 & 0 \\
\hline E5 & 0 & 1 & 1 & 0 & 1 & 0 & 0 & 1 & 0 & 1 & 0 & 1 & 0 \\
\hline
\end{tabular}

Font: Own elaboration.

\subsection{An Optimization Tool for Guided Design Process to Specific Market Types}

The connection between design properties and Kansei emotional values were established by a general multiple regression model, defined by:

$$
\mathrm{Y}_{\mathrm{i}}=\beta_{\mathrm{o}}+\beta_{\mathrm{n}} \mathrm{X}_{2}+\beta \mathrm{X}_{\mathrm{pi}}+\ldots . .+\beta_{\mathrm{i}} \mathrm{X}_{\mathrm{pi}}+\varepsilon_{\mathrm{i}} ; \mathrm{i}=1,2, \ldots, \mathrm{n} .
$$

This model incorporates the aesthetic-formal characteristics, registered inside the collecting data instrument, as dummy variables in the prediction process and it's expressed in a general way as follows:

$$
Y_{i}=\sum_{j=1}^{r} \sum_{k=1}^{c} \beta_{k j} \delta_{i}(j, k)
$$

Where $j=1,2, \ldots r$ ( $r$ is total number of properties), and $k=1,2, \ldots c_{j}\left(c_{j}\right.$ is the total number of variations that every property can take). $\delta_{i^{\prime}}$ is the dummy variable 
of the property that represents a design character that will be accomplished with the product properties " $i$ ". Corresponding to the determined value in the variable $X_{p i}$ expressed in (2).

The aim is to obtain the value of the $\beta_{j k}$ coefficient such that observed value $Y_{i}$ varies almost nothing respect to the obtained prediction value, $\hat{Y}_{i}$.

After applying QT1 synthesis model correlating the $K T$ and design properties, we obtain Tables 4 - 10. it's important to stand out from this tables the importance of Property Coefficient (PC) and the value of Category Score (CS) whose interpretations are, the correlation between each property with the Kansei and the value of each sub-property to take design decisions respectively. According with the results obtained en the variations values equal or upper to 1 , these indicate a high correlation. In contrast, values equal or lower to 0 , indicate inexistence of this correlation, denoting the option that can determine the aesthetic-formal definition, will be defined by those variables with positive values.

Table 4 - Correspondence between properties and sub-properties related to the KT Herbal.

\begin{tabular}{|c|c|c|c|c|c|}
\hline$K T$ & CCM & $C P$ & PROPERTY & SUB-PROPERTY & CS \\
\hline \multirow{13}{*}{ Herbal } & \multirow{13}{*}{1} & 0.01 & Graphic language & Fotography & -0.5 \\
\hline & & & & Vector & 0.5 \\
\hline & & 0.44 & Biomimicry & Zoomorphic & -2.7 \\
\hline & & & & Herbal & 2.66 \\
\hline & & 0.02 & Finish & Matte & 0.66 \\
\hline & & & & Glossy & -0.7 \\
\hline & & 0.84 & Element distribution & Symmetric & 4.5 \\
\hline & & & & Asymmetrica & -4.5 \\
\hline & & 0.44 & Element concentration & Saturated & -2.7 \\
\hline & & & & Clean & 2.66 \\
\hline & & & & Monochromatic & 4.5 \\
\hline & & 0.84 & Color combination & Complementary & -4.5 \\
\hline & & & & Analogous & 0 \\
\hline
\end{tabular}

Font: Own elaboration. 
Table 5 - Correspondence between properties and sub-properties related to the KT Smells.

\begin{tabular}{|c|c|c|c|c|c|}
\hline$K T$ & CCM & $C P$ & PROPERTY & SUB-PROPERTY & CS \\
\hline \multirow{13}{*}{ Smells } & \multirow{13}{*}{1} & \multirow{13}{*}{0.66} & Graphic language & Fotography & \multirow{13}{*}{0} \\
\hline & & & & Vector & \\
\hline & & & Biomimicry & Zoomorphic & \\
\hline & & & & Herbal & \\
\hline & & & Finish & Matte & \\
\hline & & & & Glossy & \\
\hline & & & \multirow[t]{2}{*}{ Element distribution } & Symmetric & \\
\hline & & & & Asymmetric & \\
\hline & & & Element concentration & Saturated & \\
\hline & & & & Clean & \\
\hline & & & \multirow{3}{*}{ Color combination } & Monochromatic & \\
\hline & & & & Complementary & \\
\hline & & & & Analogous & \\
\hline
\end{tabular}

Font: Own elaboration.

Table 6 - Correspondence between properties and sub-properties related to the KT Practical.

\begin{tabular}{|c|c|c|c|c|c|}
\hline KT & CCM & $C P$ & PROPERTY & SUB-PROPERTY & CS \\
\hline \multirow{13}{*}{ Practical } & \multirow{13}{*}{1} & 0.06 & Graphic language & Fotography & 0.75 \\
\hline & & & & Vector & -0.8 \\
\hline & & 0.16 & Biomimicry & Zoomorphic & -1 \\
\hline & & & & Herbal & 1 \\
\hline & & 0.07 & Finish & Matte & 0.66 \\
\hline & & & & Glossy & -0.7 \\
\hline & & 0.06 & Element distribution & Symmetric & 0.75 \\
\hline & & & & Asymmetrica & -0.8 \\
\hline & & 0.56 & Element concentration & Saturated & -1.8 \\
\hline & & & & Clean & 1.83 \\
\hline & & & & Monochromatic & 0.75 \\
\hline & & 0.06 & Color combination & Complementary & -0.8 \\
\hline & & & & Analogous & 0 \\
\hline
\end{tabular}

Font: Own elaboration. 
Table 7 - Correspondence between properties and sub-properties related to the $K T$ Taste.

\begin{tabular}{|c|c|c|c|c|c|}
\hline$K T$ & CCM & $C P$ & PROPERTY & SUB-PROPERTY & CS \\
\hline \multirow{13}{*}{ Taste } & \multirow{13}{*}{1} & 0.37 & Graphic language & Fotography & -2.3 \\
\hline & & & & Vector & 2.25 \\
\hline & & 0.02 & Biomimicry & Zoomorphic & 0.5 \\
\hline & & & & Herbal & -0.5 \\
\hline & & 1 & Finish & Matte & 3 \\
\hline & & & & Glossy & -3 \\
\hline & & 0.16 & Element distribution & Symmetric & 1.5 \\
\hline & & & & Asymmetrica & -1.5 \\
\hline & & 0.44 & Element concentration & Saturated & -2 \\
\hline & & & & Clean & 2 \\
\hline & & & & Monochromatic & 1.5 \\
\hline & & 0.16 & Color combination & Complementary & -1.5 \\
\hline & & & & Analogous & 0 \\
\hline
\end{tabular}

Font: Own elaboration.

Table 8 - Correspondence between properties and sub-properties related to the KT Natural.

\begin{tabular}{|c|c|c|c|c|c|}
\hline KT & CCM & $C P$ & PROPERTY & SUB-PROPERTY & CS \\
\hline \multirow{13}{*}{ Natural } & \multirow{13}{*}{1} & 0.34 & Graphic language & Fotography & 2 \\
\hline & & & & Vector & -2 \\
\hline & & 0.92 & Biomimicry & Zoomorphic & -2.7 \\
\hline & & & & Herbal & 2.66 \\
\hline & & 0.003 & Finish & Matte & -0.2 \\
\hline & & & & Glossy & 0.16 \\
\hline & & 0.34 & Element distribution & Symmetric & 2 \\
\hline & & & & Asymmetrica & -2 \\
\hline & & 0.13 & Element concentration & Saturated & -1 \\
\hline & & & & Clean & 1 \\
\hline & & & & Monochromatic & 2 \\
\hline & & 0.34 & Color combination & Complementary & -2 \\
\hline & & & & Analogous & 0 \\
\hline
\end{tabular}

Font: Own elaboration. 
Table 9 - Correspondence between properties and sub-properties related to the KT Texture.

\begin{tabular}{|c|c|c|c|c|c|}
\hline$\kappa T$ & CCM & $C P$ & PROPERTY & SUB-PROPERTY & CS \\
\hline \multirow{13}{*}{ Texture } & \multirow{13}{*}{1} & 0.007 & Graphic language & Fotography & -0.3 \\
\hline & & & & Vector & 0.25 \\
\hline & & 0.04 & Biomimicry & Zoomorphic & -0.5 \\
\hline & & & & Herbal & 0.5 \\
\hline & & 0.70 & Finish & Matte & 2 \\
\hline & & & & Glossy & -2 \\
\hline & & 0.11 & Element distribution & Symmetric & 1 \\
\hline & & & & Asymmetrica & -1 \\
\hline & & 0.31 & Element concentration & Saturated & -1.3 \\
\hline & & & & Clean & 1.33 \\
\hline & & & & Monochromatic & 1 \\
\hline & & 0.11 & Color combination & Complementary & -1 \\
\hline & & & & Analogous & 0 \\
\hline
\end{tabular}

Font: Own elaboration.

Table 10 - Correspondence between properties and sub-properties related to the KT Quality.

\begin{tabular}{|c|c|c|c|c|c|}
\hline$K T$ & $C C M$ & $C P$ & PROPERTY & SUB-PROPERTY & CS \\
\hline \multirow{13}{*}{ Quality } & \multirow{13}{*}{1} & 0.02 & Graphic language & Fotography & 0.5 \\
\hline & & & & Vector & -0.5 \\
\hline & & 0.29 & Biomimicry & Zoomorphic & -1.5 \\
\hline & & & & Herbal & 1.5 \\
\hline & & 0.43 & Finish & Matte & 1.83 \\
\hline & & & & Glossy & -1.8 \\
\hline & & 0.26 & Element distribution & Symmetric & 1.75 \\
\hline & & & & Asymmetrica & -1.8 \\
\hline & & 0.29 & Element concentration & Saturated & -1.5 \\
\hline & & & & Clean & 1.5 \\
\hline & & & & Monochromatic & 1.75 \\
\hline & & 0.26 & Color combination & Complementary & -1.8 \\
\hline & & & & Analogous & 0 \\
\hline
\end{tabular}

Font: Own elaboration. 


\subsection{Briefing Model Construction}

In relation with the different Kansei, the tags that obtained a high relation with the enterprise philosophy are the: $K T_{1}: \mathrm{Herbal}_{1} \mathrm{KT}_{5}$ : Natural. In consequence, the design requirements will have to contain the described aspects in the properties and subproperties specified for each Kansei in tables $\mathbf{4}$ and $\mathbf{8}$. Using the sketch technique, a close reference to the possible solution of design and image for the product (Fig. 6 . and 7.) was generated, coherently with the requirements expressed above.

Natural: Inside its graphic language, it must be used photography as main composition resource, herbal references as leaves, stems, roots, among other organic representations. About the manufacture, material what it's made the packing must have a matte finish and the pigments color used for graphics must be constituted by a monochromatic palate with different value graduations. Other aspects as compositive elements distribution and rhythm; it has to be distributed symmetrically and maintain blank spaces (intervals between body to another), avoiding to generate saturated elements zones. (Fig. 6.)

Fig. 6 - Formal approximation to the obtained design for Kansei Tag Natural.

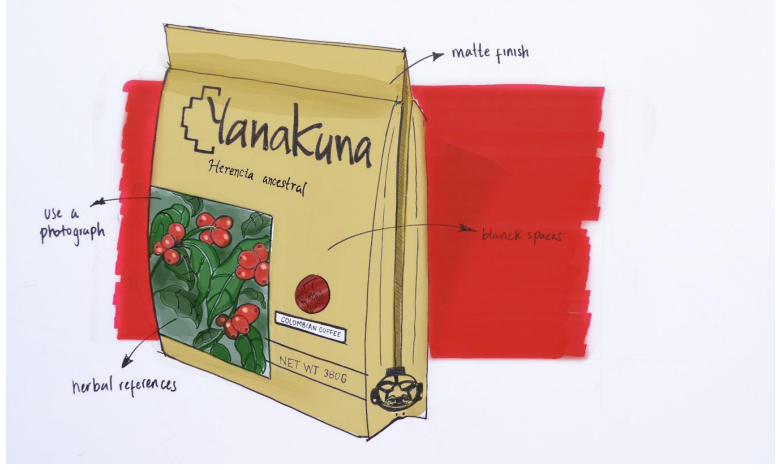

Fonte: Own elaboration. 
Herbal: Inside its graphic language, it must be used the vector as main composition resource, herbal references as leaves, stems, roots, among other organic representations. About the manufacture, material what it's made the packing must have a shine finish and the pigments color used for graphics must be constituted by a monochromatic palate with different value graduations. Other aspects as compositive elements distribution and rhythm; it has to be distributed symmetrically and maintain blank spaces (intervals between body to another), avoiding to generate saturated elements zones. (Fig. 7.)

Fig. 7 - Formal approximation to the obtained design for Kansei Tag Herbal.

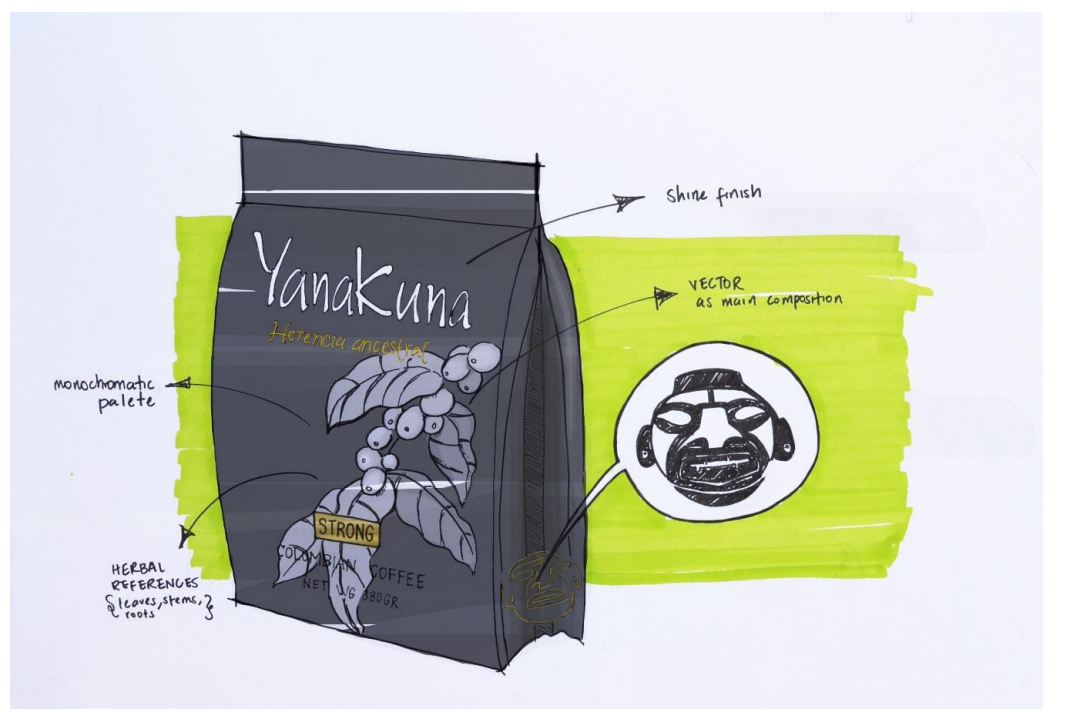

Fonte: Own elaboration.

\section{DISCUSSION}

In the framework of tools appropriation coming from the Kansei engineering, were evidenced multiples strategies for property identification contained in the product 
universe, the use of a predictive model allowed to parameterize the behavior of variation, reducing the uncertainty level, speculation and subjectivity in the aesthetic-formal design process of product image and packing.

One of the aspects of most importance in the methodology implementation, was the emotional aspect integration, being a key factor in the product addressing, because implied to identify reflexive needs of the consumer hosted in the objective market niche. During the process, was made emphasis in the different languages intercepted in every step that showed the multiple dimensions that an abstract design model can mutate.

\section{CONCLUSION}

It was recognized that subjectivity reduction in the launching of a new product in the market propitiate a successful scenario, especially for those young organizations. The model proposed direct its elections to the real market factors where the new product would be launched. Making a precise tracing to the process allows to make constantly improvements, identify the reasons of success and mistakes that conforms the base of a replicable and adaptable model to multiple product design exercises. The model, stands out language diversity, though adds considerable tools to designer, and adds complexity to the sequence as well, reducing the access to some market sectors that pretends to beneficiate of the tool. It would be interesting to project model validity in its interaction with the target audience, a continuation of the investigation that allows validate the use of methodological tools as the Kansei engineering in this new consumption markets. 


\section{BIBLIOGRAPHIC REFERENCES}

1. ALONZO, Julio César; MUNOZ, André's Felipe. Interpretacion de variables Dummy en modelos log-lin. Apuntes de Economía, Valle del Cauca, n. 40, 2014.

2. AVENDAÑO PRIETO, Gerardo; ÁlVAREZ, Héctor René. Aplicación de la ingeniería kansei con redes neuronales. Avances Tecnológicos en Ingeniería, Cundinamarca, v. 1, n. 1, p. 7-27, 2013.

3. BRIEDE WESTERMEYER, Juan Carlos; CABELLO MORA, Marcela; HERNANDIS ORTUÑO, Bernabé. Modelo de abocetado concurrente para el diseño conceptual de productos industriales. Dyna, Bogotá, v. 81, n. 187, p. 199-208, 2014.

4. CÉSPEDES, Pablo Buriticá. La roya del cafeto en Colombia: Realizaciones de impacto nacional e internacional en el siglo XX. Revista Facultad Nacional de Agronomía Medellín, Medellín, v. 63, n. 1, p. 5285-5292, 2010.

5. CÓRDOBA-ROLDÁN, Antonio; AGUAYO-GONZÁLEZ, Francisco; LAMA-RUIZ, Juan. Ingeniería kansei: diseño estético de productos. Dyna, Bogotá, v. 85, n. 6, p. 489-503, 2010.

6. CROSS, Nigel. Métodos de diseño: estrategias para el diseño de productos. México DF: Limusa Wiley, 2005.

7. FEDERACIÓN NACIONAL DE CAFETEROS DE COLOMBIA. Nuestras regiones cafeteras. 2010. Disponible en: http://www.cafedecolombia.com/ particulares/es/la_tierra_del_cafe/regiones_cafeteras/. Acceso en: 6 nov. 2019
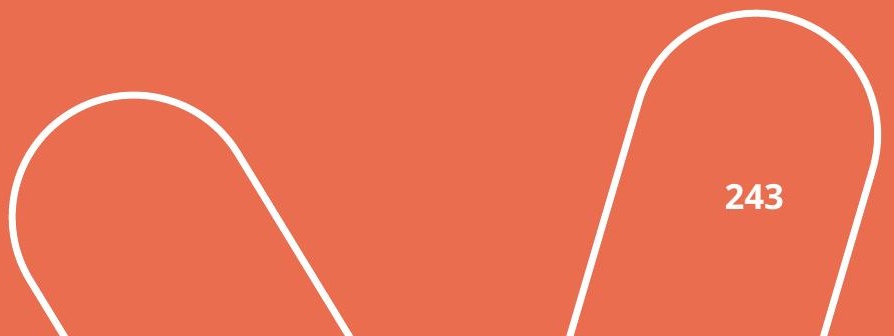
Projética, Londrina, v. 11, n. 3 Esp IFDaP, p. 225-245, novembro 2020

8. HUANG, Yuexiang; CHEN, Chun-Hsien; KHOO, Li Pheng. Kansei clustering for emotional design using a combined design structure matrix. International Journal of Industrial Ergonomics, Amsterdam, v. 42, n. 5, p. 416-427, 2012 a.

9. HUANG, Yuexiang; CHEN, Chun-Hsien; KHOO, Li Pheng. Products classification in emotional design using a basic-emotion based semantic. International Journal of Industrial Ergonomics, Amsterdam, v. 42, n. 6, p. 569-580, 2012 b.

10. HUANG, Yuexiang; CHEN, Chun-Hsien; WANG, Cindy I-Hsuan; KHOO, Li Pheng. A product configuration analysis method for emotional design using a. International Journal of Industrial Ergonomics, Amsterdam, v. 44, n. 1, p. 120$130,2014$.

11. KHEAN CHUAN, Ngip; SIVAJIA, Ashok; MOHAMAD SHAHIMIN, Mizhanim; SAADB, Nursyakinah. Kansei engineering for e-commerce sunglasses selection in Malaysia. Procedia: social and behavioral sciences, Rotterdam, v. 97, n. 6, p. 707-714, 2013.

12. NAGAMACHI, Mitsuo. Kansei engineering as a powerful consumer-oriented technology for product development. Applied Ergonomics, Guildford, v. 33, n. 3, p. 289-294, 2002.

13. NAGAMACHI, Mitsuo. Kansei engineering: a new ergonomic consumeroriented technology for product development. International Journal of Industrial Ergonomics, Amsterdam, v. 15, n. 1, p. 3-11, 1995.

14. NAGAMACHI, Mitsuo. Perspectives and the new trend of Kansei/affective engineering. The TQM Journal, London, UK, v. 20, n. 4, p. 290-298, 2008. 


\section{Emotional design model as alternatye...market}

MURILLAS, J. S.; BARCO, J. S. M.; DIAZ L. M. P.

15. PAISAJE CULTURAL CAFETERO. Cultura cafetera: un paisaje productivo muy cultural. 2017. Disponible en: http://paisajeculturalcafetero.org.co/ contenido/Cultura-Cafetera. Acceso en: 6 nov. 2019.

16. PERKS, Helen; COOPER, Rachel; JONES, Cassie. Characterizing the Role of Design in New Product Development: An Empirically Derived Taxonomy. The Journal of Product Innovation Management, Hoboken, NJ, v. 22, n. 2, p. 111-127, 2005.

17. RIAÑO, Noelia Cigüenza. Huila es el departamento líder cafetero con $16 \%$ del área cultivada. La Republica, Bogotá, 18 mar. 2019. Dinponible en: https:// www.larepublica.co/especiales/ruta-del-cafe/huila-es-el-departamentolider-cafetero-con-16-del-area-cultivada-2840686. Acceso en: 6 nov. 2019.

18. SEMANATE QUIÑONEZ, Hugo Alexánder. Producción de café de alta calidad por comuneros de la comunidad indígena Yanacona en el sur del Huila Colombia: un análisis de aglomeración espacial. Agroecologia: ciencia e tecnología, Huila, v. 2, n. 1, p. 6-4, 2014.

19. TRUEMAN, Myfanwy; JOBBER, David. Competing through design. Long Range Planning, London, UK, v. 31, n. 4, p. 594-605, 1998.

20. YANG, Sun-Mo; NAGAMACHI, Mitsuo; LEE, Soon-Yo. Rule-based inference model for the Kansei Engineering System. International Journal of Industrial Ergonomics, Amsterdam, v. 24, n. 5, p. 459-471, 1999.

\section{ACKNOWLEDGMENTS}

We want to thank to Alicafeh by letting us to make this study inside its products portfolio and the linkage with the consumers participants of this study. 